\title{
ENTRE MITO Y LOGOS: INTERPRETACIÓN SOBRE LA IMPORTANCIA DEL MITO EN EL ORIGEN DEL CONCEPTO DE LA ECONOMÍA
}

\author{
BETWEEN MYTH AND LOGOS: INTERPRETATION \\ OF THE IMPORTANCE OF MYTH FOR THE \\ INCEPTION OF THE CONCEPT OF ECONOMY
}

\author{
ENTRE MITO E LOGOS: UMA INTERPRETAÇÃO \\ SOBRE A IMPORTÂNCIA DO MITO NA ORIGEM DO \\ CONCEITO DA ECONOMIA
}

Edward Andrés Tamayo Duque*

\section{RESUMEN}

A diferencia de lo que sucede en la actualidad, durante la antigüedad griega, la economía no se estructuraba como una rama de la ciencia designada a estudiar el comercio, la riqueza, ni la distribución de los recursos de la sociedad; por el contrario, era un asunto doméstico, donde para el hombre griego el hogar era el centro de su responsabilidad como buen ciudadano: gobernándose y luego gobernando su

* Magíster en Filosofía de la Universidad Pontificia Bolivariana. Doctorando en Filosofía de la misma universidad. Administrador de Negocios Internacionales de la Universidad Pontificia Bolivariana (Medellín). Docente investigador de la Universidad San Buenaventura. Este artículo de reflexión, vinculado a la línea de investigación "Globalización e Interculturalidad" de la Facultad de Ciencias Empresariales de la Universidad San Buenaventura, presenta los resultados interpretativos extraídos de la Investigación de Maestría en Filosofía de la Universidad Pontificia Bolivariana titulada "El cuidado de sí desde el oikos-nomos: hacia un restablecimiento del vínculo entre ética y economía". Correo electrónico: edward.tamayo@usbmed.edu.co ORCID ID: 0000-0002-7407-6775

Artículo recibido el 8 de marzo de 2016 y aprobado para su publicación el 3 de octubre de 2016. 
propiedad. Este artículo, desarrollará así un análisis sobre el origen primario de las prácticas de la economía en los mitos de Hestia, Hermes, Deméter y Cibeles. Así, partiendo de su raíz etimológica, se realizará una interpretación sobre estos cuatro dioses, otorgando elementos básicos para demostrar que el concepto de la economía es incluso anterior al discurso socrático de la época clásica, y cómo, partiendo de la interpretación del mito, es posible encontrar unas marcas que definen una serie de prácticas que posteriormente sirvieron para designar un valor a dicho concepto.

\title{
PALABRAS CLAVE
}

Economía, Mitos, Logos, Dioses griegos, Interpretación.

\begin{abstract}
Unlike what happens nowadays, Economy in Ancient Greece was not seen as a branch of science dedicated to the study of trade, wealth or distribution of resources. On the contrary, it was a domestic issue. For Ancient Greeks, home was the center of their responsibilities as good citizens: governing themselves and governing their proprieties. The aim of the article is to analyze the primitive origin of economic practices within the myths of Hestia, Hermes, Demeter, and Cybele. Therefore, beginning with the etymological root of the word, an interpretation of these four gods is proposed, which provides elements to argue that the concept of Economy appears earlier than the Socratic discourse of the Classical Period. Through an interpretation of the myth, it is also possible to identify some signs that outline a series of practices, which subsequently were crucial to attach a value to this particular concept.
\end{abstract}

\section{KEY WORDS}

Economy, Myths, Logos, Greek Gods, Interpretation.

\section{RESUMO}

A diferença do que ocorre na atualidade, durante a antiguidade grega a economia não se estruturava como um galho da ciência designada a estudar o comércio, a riqueza nem a distribuição dos recursos da sociedade, pelo contrário, era um assunto doméstico. Para o homem grego o lar foi o centro de sua responsabilidade como bom cidadão: governando-se e depois governando sua propriedade. Este artigo desenvolverá uma análise sobre a origem primária das práticas da economia nos mitos de Héstia, Hermes, Deméter e Cibele, de maneira que, partindo de sua raiz etimológica, realize uma interpretação sobre esses quatro deuses, fornecendo elementos básicos para demonstrar que o conceito da economia é inclusive anterior ao discurso socrático da época clássica. E, assim, demonstrar como partindo da interpretação do mito, é possível encontrar umas marcas que definem uma série de práticas que, posteriormente, serviram para designar um valor a esse conceito.

\section{PALAVRAS-CHAVE}

Economia, Mitos, Logos, Deuses gregos, Interpretação. 


\section{Introducción}

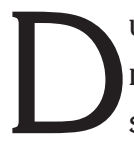

urante la Antigüedad, el advenimiento del logos racional representó una interiorización particular del conocimiento que no solo marcó el cambio discursivo entre la era arcaica y clásica, sino que además permitió la apertura a una nueva forma de pensamiento que originó la separación radical entre sophistes y sophos. A partir de esta separación emergió el discurso de la filosofía y con esta, la discusión respecto a diferentes artes y ciencias, entre las cuales se encontraba la oikonomia.

Proveniente del griego oikos-nomos, la economía traduciría inicialmente las normas en el hogar; aunque vale la pena mencionar que la palabra oikos proviene a su vez de oikia y también hace mención a un centro sólido, cálido, estable, donde no solo se encuentran todas las pertenencias, sino las personas que conviven allí y que posteriormente los romanos llamarán con la denominación latina familia (Finley 18).

Estas características fueron propias del concepto clásico de economía, pero es oportuno reconocer que su práctica es anterior, en tanto el estudio de la oikonomia no llegó al mundo sin una figura que constituyera su núcleo conceptual. En otras palabras, antes del surgimiento de su estudio existió una configuración similar respecto al ideal práctico del gobierno del hogar, que fue pertinentemente representado a partir de la figura idílica de los Dioses y Héroes de los relatos míticos.

En el presente artículo se pretende demostrar cómo las bases del concepto de la oikonomia habían comenzado a estructurarse a partir del mythos, es decir, dentro de la representación idílica de aquellos conceptos que en la imagen de los dioses se encontraban ligados a diversos elementos qué valorar por parte del gobernante del hogar. En este sentido, la reflexión propuesta girará en torno a los siguientes tres elementos:

El primero, relativo a la representación que tuvo la fertilidad para la economía desde la perspectiva cosmogónica del Timeo de Platón. El segundo, concerniente a la representación que Hestia, Hermes, Cibeles 
y Deméter significan para el gobernante y los gobernados del hogar. Finalmente, se concluirá, tomando las marcas que desde la perspectiva de estos mitos permiten vincular el discurso arcaico con el clásico socrático, cómo se conforma la imagen del buen gobernante.

\section{Fertilidad y oikos en la arcadia idílica}

Según Jean Pierre Vernant, existe un ideal de valor y de virtud que subyace en la significación de los relatos heroicos de los dioses griegos; y a su vez estos encuentran su esencia en el ámbito de "[...] una sacralidad omnipresente que reviste diversas formas en términos de un uso dentro de los límites permitidos" (Sociedad 109). Esta denominación no sería ajena al orden de prácticas de la economía, dado que en la era arcaica también se reflejaba dicha sacralidad a partir de los relatos que pretendían dar respuesta a determinada configuración de los hábitos, valores y costumbres del económico griego.

De acuerdo con los estudios de Claude Mossé, el económico griego se puede representar bajo la figura del campesino propietario, aquel personaje que en Los Arcanienses de Aristófanes es un ser independiente que vive de sus cultivos y del cuidado de su propiedad. El oikonomikos (económico) arcaico no pretendía buscar la estructuración de las normas de conducta para el gobierno del hogar; sus prácticas se estructuraban en sí mismas como un himno de batalla para hacer frente a los retos que impone la vida en todas sus situaciones, incluidas también las situaciones límite.

Es en este sentido como los relatos mitológicos se incorporan para estructurar la virtud del económico que posteriormente tomaría la filosofía clásica; es decir, en la medida en que las historias de determinados dioses liberaban la forma de un saber particular, un ethopoien que generaba un proceso de transformación, partiendo de la significación artística, poética, sobre las condiciones de vida del campesino griego.

El mito es por consiguiente un elemento clave para entender el ideal general del económico, pues a partir de este el ser humano accedió a 
una forma del saber que no poseía, que representó conocimiento de sí en la imagen de los dioses y que se manifestó a partir de un proceso de transformación espiritual, del entendimiento del mundo como imagen de aquello que habita en una relación micro y macro cósmica, donde la imagen y el reflejo frente al mundo le otorgaban los elementos necesarios para una transformación vital de sí - ethopoien - y del ethos de los otros -ethopoios - (Foucault, Palabras 300).

La ethopoiesis del económico se puede entender así como un proceso de transformación de sí y de los otros, una conversión de sí como gobernante y los otros como gobernados, pues aquel es quien da el ejemplo y cuida de las personas que habitaban el centro estable y cálido del hogar. Es por ello que para el económico la sabiduría no se estructuraba como una serie de datos aislados, sino que significaba una nueva forma de entenderse como un ser justo y virtuoso, como en el caso del mito, tomando la representación cosmogónica de la fertilidad.

Un ejemplo claro de esta afirmación se ve reflejado en la figura de Odiseo en la obra de Homero. Allí se puede apreciar cómo para el gobernante del hogar la primera responsabilidad siempre ha estado en consonancia con el ideal del retorno al hogar: de hacer de los gobernados lo más bello y virtuoso posible. En el económico se gesta la primera figura del maestro prudente, del gobernante que en un sentido estricto ha cuidado de sus bienes con la sabiduría práctica que le da el amor por la vida de sus hijos.

Es por esto que, desde la perspectiva de la fertilidad, un hombre justo es aquel que luego de enormes esfuerzos, sacrificios, tedios, horrores y pesadumbres, aún tiene la gracia para seguir cuidando y beneficiando a los otros, dando a cada quien lo que merece, pues el sentido de dar y recibir beneficios con justicia siempre se vio reflejado en el campesino griego a la hora de recoger sus cosechas. Una evidencia la encontramos en Hesíodo:

A ella la parió primera la Noche tenebrosa y la puso el Crónida de alto trono que habita en el éter dentro de las raíces de la tierra, y es mucho más útil para los hombres: ella estimula al trabajo incluso al holgazán; pues todo el que ve rico a otro que se desvive en arar o plantar y procurarse una buena casa, está ansioso por el trabajo (Op. 20). 
El ideal griego de hombre justo se ve aquí plasmado en aquel da todo con la simple esperanza de gratificación, en quien hace siempre algo bueno por otros esperando solo las gracias de la fortuna. Para los griegos esto se traduce en términos de la fortuna de la fertilidad, dado que cuidando sus hijos, propiedades y cosechas y siendo el modelo a seguir para sus gobernados, es como mejor cuidaban del bienestar de su cultura y sociedad.

Para Jenofonte esta es la representación fiel de la figura del hombre justo, quien cultiva óptimamente algún bien, quien entiende que sus esfuerzos no solo le proveen libertad, sino que además hace que otras vidas se ejerciten en el conocimiento de la gratitud y de aquellas prácticas que no se encuentran atadas simplemente a lo material.

Según se puede interpretar en el Timeo de Platón, la fertilidad fue por muchos años la explicación más sensata sobre el origen del universo, del hombre y de todas las cosas, y por ello esta visión aparece proyectada sobre el ser humano a través de la agricultura, uno de los ejercicios que dependiendo de la fortuna, necesariamente obligaban al económico a pensar y comprender la imagen de elementos fundamentales para la economía.

En síntesis, una de las primeras formas para el ser humano de entenderse a sí mismo en el mundo fue la agricultura, y por esto al indagar sobre los principios de la economía es imperativo referenciar la relación estrecha que existió entre el hombre, los dioses y la tierra; entre la fecundidad, la educación y la expansión de la cultura griega; esta fue la significación primaria de la economía y por esta misma razón la economía fue la formación estricta en los cuidados de las tierras de los hombres y mujeres de toda polis griega.

En el texto "El hombre y la Economía" es posible observar cómo las gracias de la fertilidad dependieron de una tierra fértil, de una familia numerosa, y en los relatos de Hesíodo y Aristófanes se encuentra además el ideal de virtud en la templanza del cultivo de la tierra. Cultivar la familia y extender la producción era para los griegos uno de los retos más significativos porque, en la mayoría de los casos, les exigía dar 
prueba de su fortaleza para el trabajo y así, ser dignos de recibir las gracias de la madre tierra (Mossé 35).

Desde la perspectiva cosmogónica, la fertilidad también se establecía por medio de la relación de los dioses con la tierra, no en vano el límite que Cronos impone a Urano sobre la fertilidad de Gea, no es más que la transición hacia un carácter doméstico que se ve plasmado en el hombre a partir de las prácticas de la agricultura; pero además, este determina el origen de una nueva concepción como fue la del adentro, la del interior, de un centro estable que necesita del orden y el autocontrol.

Según estos argumentos no es una coincidencia que la primogénita de Cronos fuera la diosa del hogar Hestia. En palabras de Vernant, Gea, la oscura tierra, fue separada de Caos, la luz del día, porque su fertilidad infinita y desordenada necesitaba un orden (Política 118). Urano realizó esta separación y luego fue castrado por Cronos, quien representando la noción del tiempo, de la necesidad del control en el placer de la unión sexual y de la justa medida, delimitó el paso de un mundo natural y salvaje a uno cultivado y civilizado (Platón, Ti. 31b).

El origen del universo en el mito griego es un parto poético del tiempo y del orden a causa de la separación entre Gea y Caos, es una enseñanza sobre los orígenes mismos de la cultura, de la sociedad, la civilización, la vida en comunidad, en el hogar y en familia. En esta relación con el mundo y los dioses, cada hombre que nace es un nuevo agricultor que da vida y cada mujer es una nueva madre de la tierra y la fertilidad.

Las marcas de la oikonomia en los mitos de Hestia, Hermes, Cibeles y Deméter

Según la interpretación de Jean Pierre Vernant, los dioses griegos estuvieron revestidos de una sacralidad omnipresente que los convirtió en modelo de conducta para el Heleno, y cada una de estas prácticas estaba revestida por la representación de algún Dios (Sociedad 109). 
Al interpretar las marcas que subyacen en los relatos mitológicos, es importante destacar que los Dioses griegos se podían identificar en su esencia respecto a un ideal de virtud particular que los identificaba con un Arte específico como lo eran la política, la economía, la navegación, la guerra, la oratoria, la retórica, entre otros.

Al indagar respecto a los fundamentos de la economía en el periodo griego, y si bien en todos los dioses hay elementos para establecer una enseñanza puntual frente al gobierno y a las prácticas en el hogar, se puede encontrar cuatro dioses que permiten realizar un análisis puntual respecto a las prácticas que mejor definen el ideal de virtud de quienes residen en el hogar, de quien lo gobierna y a su vez aprende a gobernar según para las acciones que configuran al ser económico de la época; estos dioses son: Hestia, Hermes, Cibeles y Deméter.

Según el Diccionario mitológico de Pierre Grimal: Hestia, es la diosa del hogar, del calor y del fuego sagrado (233); Hermes, mensajero, intérprete, comerciante, pastor y dueño de toda transición y transacción económica y comercial (222); Deméter, madre distribuidora, diosa de la agricultura y del matrimonio (124); y por último, Cibeles, diosa de las murallas y la personificación de la fertilidad en las cosechas (107).

Mencionada en muy pocos relatos, Hestia fue la diosa del oikos, quien cuidaba del interior del hogar; literalmente la Diosa de la oikonomia. Dentro de sus características aparece como una diosa virgen, era la representación de un núcleo circunscrito, tenía el rol de contener en el hogar al grupo humano, era pacífica y dedicada a su estado virginal. "El rol de Hestia era hacer del hogar un centro estable, permanente, un interior donde se acumulen, bajo la custodia de la diosa, las riquezas atesoradas en el fondo de la morada" (Vernant, Política 106).

Como Diosa del hogar Hestia era sagrada, tanto que incluso se le daba gracias a ella antes que a Zeus en el momento de recibir los alimentos. Debido a su carácter pacífico, también se puede ver en ella una imagen de virtud para las hijas, quienes siendo jóvenes, eran educadas en la humildad, docilidad y pasividad, valores que permitían preservar el centro 
estable de la familia. El rol de Hestia en la sociedad griega se entendía más allá del simple hecho de ser un referente de conducta, ella era el núcleo de estabilidad del hogar y por ende de la sociedad.

Normalmente, se tiende a considerar que en la sociedad griega, el rol femenino fue limitado a la reproducción y al cuidado de los hijos, pero en clave de la economía esta interpretación no sería acertada. En el Económico, Jenofonte demuestra que la mujer en Grecia era desposada para ser educada en las labores administrativas del hogar y por esto, tarde o temprano se transformaba en gestora y administradora. Bajo la representación de Hestia, el rol femenino significó entonces la paz, el cuidado de la virginidad y el aprendizaje de la debida gestión y administración de todo aquello que pertenece al interior del hogar y la propiedad.

Una de las características que relacionará el mito de Hestia con las marcas del discurso de la economía durante la era clásica, puede así verse expuesta por Jenofonte al afirmar:

Yo creo que si la mujer es buena colaboradora en la hacienda, contribuye tanto como el marido a su prosperidad. El dinero entra en general en la casa gracias al trabajo del hombre, pero se gasta la mayoría de las veces mediante la administración de la mujer. Si esta administración es buena, la hacienda aumenta, si es mala, la hacienda se arruina (Oec. 15).

El hombre era el modelo a seguir, era el jefe, la cabeza visible al mando del hogar, metafóricamente era guiado por Apolo -el arquitecto y dios de las técnicas-, Dionisio -inspirador del éxtasis de verano que hacía crecer los viñedos- y Hermes -el pastor y comerciante-. La mujer por otra parte, era quien al servicio del hogar administraba prudentemente todos los asuntos relativos a la riqueza, heredera de la fértil Gea, protectora y patrona del calor interior.

Robert Graves relaciona los cultos en honor a la imagen de esta Diosa con "un montón de carbón de leña ardiente que se mantenía encendido en el centro del hogar cubriéndolo con ceniza blanca" (51). De acuerdo con este escritor británico, dicho culto obedece a que el carbón cubierto con 
ceniza constituía la manera más agradable y económica de calefacción en la Antigüedad, en tanto no producía humo ni llamas y formaba el centro natural de las reuniones de la familia o el clan. En sus propias palabras: "En Delfos el montón de carbón de leña fue trasladado a un recipiente de piedra caliza para el uso al aire libre y se convirtió en el omphalos, o protuberancia del ombligo, que aparece con frecuencia en las pinturas de los jarrones griegos" (52).

El omphalos señalaba el centro del mundo para el habitante griego y en él aparece inscrito el nombre de la Madre Tierra, uniendo así el ritual del interior, correspondiente a Hestia, con el exterior y el mundo, relativo a Gea. En conclusión, la "oikia" griega era calor, amor, fraternidad, seguridad, felicidad personal y también hospitalidad (Soto 546).

En los Himnos homéricos, Hestia mantuvo un trato cordial con todos los dioses pero Hermes siempre fue su favorito; desde el exterior Hermes relataba las historias y desgracias de todos los Dioses y seres humanos (Graves 51). Por el contrario, Afrodita, con su representación erótica, fue una diosa cuyo comportamiento siempre desaprobó Hestia, ya que era completamente opuesta al carácter de virtud al cual se había dedicado aquella.

Hermes fue el proveedor y comerciante, fue un pastor dedicado a diversas labores públicas que exigían para la correcta economía un constante tránsito entre el interior y el exterior. Uno de los ejemplos que aparece bajo esta mirada es el cántico de Homero dedicado a Odiseo; su historia demuestra que en el constante ir y venir, las labores del económico estaban demarcadas por su tránsito entre el interior y el exterior, pero siempre deseando el regreso al hogar, a la calidez de aquel centro estable, que en los mitos que relacionan a Hestia y Hermes se encuentran ligados a partir de los relatos que él provee a la Diosa del hogar.

En cuanto al origen de la economía, la relación planteada por los mitos entre Hestia y Hermes permite comprender la delimitación entre las prácticas dedicadas a ambos sexos. Hermes no era simplemente un viajero movedizo, comerciante bueno en oratoria, sino que también fue 
modelo de conducta para el gobernante del hogar. Al igual que Odiseo, siempre buscaba un regreso o retorno al hogar, incluso aun cuando las prácticas sexuales no obedecieran estrictamente a la monogamia, como si sucedió durante el ascetismo cristiano.

La monogamia o la poligamia no eran necesariamente temas a debatir en esta época, el hombre siempre conocía que su papel era dar ejemplo en el gobierno de sus pasiones, y que el rol de la mujer se encontraba determinado a su prudencia y temor natural a los peligros del exterior. Como patrono de todas las transiciones y transacciones, Hermes fue determinante en las prácticas del matrimonio, por ejemplo, entregando sexualmente a la joven en su primera noche de bodas.

Según Vernant, Hermes era el amo de las transacciones y transiciones de todo tipo, era pastor, guía, mensajero, comerciante, patrono de los encuentros y los cambios, incluso de las palabras y las riquezas. Cabe señalar que, como pastor y guía, Hermes transmitía una sabiduría práctica particular en el contexto de las acciones del económico, en tanto fue el intérprete del mensaje de los dioses y también se le encomendaba la guía en las acciones del comercio que, encontrándose por fuera del oikos, fueron importantes para su estabilidad.

Atravesando muros y puertas, franqueando fronteras conduce a los vivos hasta la morada de los muertos; permite pasar de la vigilia al sueño; preside en la cámara de bodas la noche que transforma a la virgen en esposa, sigue de ida y de vuelta el camino que conduce de los dioses a los hombres (Vernant, Política 106).

La relación entre Hestia y Hermes, entre el simbolismo presente entre el interior y el exterior, fue fundamental pues en momentos de escasez, el viajero era el encargado de proveer la alimentación y con esto, el calor del hogar ya no solo dependían de Hestia, sino que además lo hacía de la buena fortuna en el intercambio de aquellos bienes que Hermes comerciaba y que finalmente los griegos en su ámbito práctico llevaron a cabo en regiones cercanas como las de Egipto y la Península itálica (Mossé 41). 
El hombre económico de la era arcaica, el campesino propietario que a veces veía la necesidad de comerciar por el bien de su hacienda, encontraba en Hermes un ejemplo claro de algunas de las tareas que desde el exterior el hombre realizaba para autoabastecerse y subsistir. En la figura idílica de Hermes es posible hallar una línea de acción ligada más al exterior que al interior del hogar; adicionalmente, en su encuentro con Hestia, se puede establecer un vínculo estrecho con la figura del oikos, en tanto fue el proveedor de los bienes.

Este vínculo tuvo importancia para dividir algunas de las labores del hombre y la mujer entre lo público y lo doméstico. Como patrono de las transiciones al presidir en la cámara de bodas la noche que transforma a la virgen en esposa, también encontró un papel determinante en la representación del matrimonio, que finalmente fue uno de los requisitos esenciales para iniciar la vida en el oikos (Platón, Leyes XI 193d).

Para Foucault, el matrimonio se constituyó con el firme propósito de procreación, responde por ende al deseo de inmortalidad y extensión de la especie que finalmente encontraba importancia en términos de la expansión de la cultura griega. No obstante, al remitirse a la representación arcaica, en la imagen de la Diosa Deméter, se puede evidenciar que el matrimonio tuvo además una significación más profunda en función de la agricultura, del cultivo de la tierra y de los hábitos que configuraron la cultura griega.

A diferencia de Hestia, Deméter no fue una Diosa virgen. Ella estuvo entregada a los dones de su fertilidad tanto en el ámbito doméstico como en función de las labores agrícolas. De su fertilidad dependieron tanto la procreación como el cultivo ordenado de las tierras y los hijos (Grimal 124). Dentro de los dominios de Deméter se incluía por ende la agricultura y la crianza de los hijos, ambas tareas estrechamente relacionadas con la sobrevivencia, la extensión de la especie, la formación de la cultura griega y el cultivo del amor por la tierra de los ciudadanos griegos.

Durante esta época, la producción de alimentos dependía primordialmente de la agricultura, y es así como la conformación del hogar fue clave en 
la medida que dependió de una familia numerosa que ayudara en los trabajos de la tierra, haciéndola y haciéndose cada vez más fértil. Deméter fue entonces la representación de la madre amorosa, es decir, del carácter del amor incondicional por la descendencia.

En el himno a esta diosa, Homero narra cómo un día recogiendo flores es engañada por Hades, quien usando un narciso hace que se alegre y se enamore perdidamente de este sentimiento. Deméter se pierde momentáneamente en su vanidad y en ese momento, "[...] cien capullos brotaron de su raíz y, al esparcirse su olor suavísimo; sonreían todo el alto y anchuroso cielo, la tierra entera y la hinchada y salobre agua del mar" (Homero, Him. 30). Al caer en este encanto, su final sería infortunado; gracias a esta distracción, Hades logró raptar a su hija Perséfone.

Mientras Deméter se dejaba guiar por el placer sensible del olor y la belleza del narciso, su hija fue llevada bajo tierra, al inframundo, por el dios de la morada de los muertos quien además le dio a Perséfone una granada, fruta muy similar a una manzana que simbolizaba el compromiso del matrimonio: "[...] Así, se abrió la tierra y surgió el soberano Polidegmón, hijo famoso de Cronos, llevado por sus corceles inmortales. Y arrebatándola contra su voluntad en carro de oro, se la llevó mientras lloraba y gritaba con aguda voz, invocando a su padre Cronida altísimo y poderosísimo" (Homero, Him. 30).

Allí, el elemento axiológico que es posible encontrar se dirige hacia todo progenitor, pero en especial a la madre, a quien el amor por sus hijos no le permite entregarse fácilmente a la vanidad. Para los griegos, su principal responsabilidad era cultivar hombres y mujeres bellas y útiles para la polis. Esta sentencia es tan drástica que, según los cantos Homéricos, Perséfone fue raptada, y en medio de la profunda tristeza de Deméter, la tierra quedó desolada, los hombres y animales corrían riesgo de extinguirse.

Zeus se vio obligado a pensar una conciliación para que las especies no se extinguieran: Perséfone permanecería junto a Hades, su esposo, la tercera parte del año, pero volvería a subir a las moradas olímpicas junto a su madre 
el tiempo restante. De este modo, "[...] en primavera sube la savia de las plantas y Deméter, feliz, cubre la tierra con un manto de vegetación durante el verano hasta que las semillas caen al suelo y se hunden en la tierra, que vuelve a conocer entonces la desolación del invierno" (Grimal 126).

El valor explicativo del mito en la significación de Deméter es evidente, pues representa la alternancia de las estaciones, el misterio de la germinación, el ciclo de la vegetación, y afirma al mismo tiempo el estrecho vínculo que existe entre el alimento, que es fuente de vida. El vínculo que une a Deméter con Hades es la tierra, pero además el hecho de que en el mito aparezca Hades no significa un elemento aislado, pues él fue un dios odiado por todos, se le nombraba despectivamente "Plutón" o "el rico", siendo el amo de las riquezas minerales que engaña los dones de la verdadera fertilidad.

Por ejemplo, el oro de los propietarios se solía guardar bajo la casa, probablemente debido a que estando allí oculto podría ser resguardado en los dominios de Hades, y nadie entraría a buscarlo porque él era aborrecido por todos (Grimal 195). De manera que la economía de la época tenía una relación bastante distante respecto a la riqueza material, las prácticas en el hogar exigían gratitud, justicia y desinterés, no se podía ser mezquino ni egoísta como lo fue Deméter.

Cuidar de los hijos fue por consiguiente un elemento recurrente, ellos fueron claves para la extensión de la cultura griega y para el cuidado de la ciudad, y en este sentido, existe una relación entre las actividades relativas al oikos y el simbolismo de la Diosa de las murallas Cibeles. Según Lleó Cañal ella fue "una salvaje Afrodita de origen frigio" heredera de la fertilidad de Gea, se representaba siempre usando un Kalathos, o especie de corona amurallada. Las murallas se usaban para proteger la ciudad contra posibles invasores, y por tanto ella era la protectora de todo aquello que se mantenía al interior de la polis (146).

Cibeles demarcó el límite entre el interior y el exterior, las fronteras entre lo salvaje y aquello que ha sido cultivado o mantenido dentro de la sociedad; como diosa amurallada mantuvo la división entre las prácticas domésticas 
y salvajes. Cibeles era una diosa salvaje, guerrera, justiciera, y por sus características enseñaba a administrar bien las riquezas. Este hecho la ubicó por fuera del carácter comúnmente femenino de la Antigüedad y la convirtió en un referente de virtud para el estereotipo de esposa que expresa Jenofonte en El económico.

Cibeles, siendo heredera de la bondad de su madre fértil Gea, ejerce su imperio sobre el mundo vegetal y, gracias a su protección, se le encomienda la buena fortuna de las labores del campo y la viticultura, ambas de fundamental importancia para que la sociedad griega se extendiera y sobreviviera. En virtud de estas características, el culto en agradecimiento a su dedicación era uno de los más importantes y consistía en colocar parte de los cultivos bordeando las murallas de la ciudad (Grimal 107).

No hay que olvidar el papel tan importante que tuvo esta deidad como diosa fecunda de la Tierra, de la Naturaleza [...] Tiene bajo su tutela los bosques de la montaña y los cultivos de la llanura. Hace brotar el nuevo verdor de los árboles y madurar los frutos [...] enseñó a sus primeros adoradores el empleo del trigo. Es la señora de las cosechas, la Cerería, la Agraria (Munilla Cabrillana 283).

Para la oikonomia, Cibeles fue importante y por ello, los habitantes de las ciudades griegas no únicamente pedían sus gracias, sino que también temían su furia, ante todo era una diosa dominante y de una crueldad particular al momento de castigarlos. En el campo de la interpretación, se puede entender que Cibeles fue un referente para la esposa madura y sabia, es decir, quien debía tomar las riendas en situaciones de orden administrativo, por ejemplo, cuidando los bienes y las riquezas.

Para Jenofonte, una mujer que no fuese dueña del hogar sino una simple esclava domesticada en su interior era de poca estima pues poco ayudaba para la debida administración de los bienes, la crianza de los hijos y la gestión de las labores de los siervos y esclavos. Cibeles representó por consiguiente la imagen protectora de las riquezas y los bienes, y es que en su relación con la economía, no se puede olvidar la importancia que tuvo su rol protector. 
Como se mencionó anteriormente, el hogar representaba el omphalos o centro del mundo, y es que en el juego entre los límites que demarcan el interior y el exterior, en términos de la importancia de la protección de la ciudad, se debe reconocer que este comienza precisamente con el debido gobierno y control de las pasiones. Una prueba de esta interpretación puede verse plasmada en La metamorfosis de Ovidio, historia que narra el mito de Atalanta e Hipómenes.

En este texto, Ovidio presenta a Atalanta y a Hipómenes completamente desbordados por una pasión erótica tan incontrolable que los lleva incluso a consumar el acto sexual en un templo dedicado a los dioses, frente a la mirada de la misma Cibeles que como castigo los transformó en leones uncidos a su carruaje, como bestias que no pueden volver a aparearse, siendo dominadas eternamente por las riendas de esta protectora amurallada (Met. 695-700).

Este mito expresa el poder quepudo ejercer Cibeles sobre el comportamiento de los amantes en términos de una economía del cuerpo y del placer; pero también, la importancia del dominio de sí que posteriormente tomó forma en el concepto de oikonomia de la era clásica. De acuerdo con este mito, vale la pena establecer que el problema económico no pasaba por la negación de los actos sexuales, sino por la problematización respecto al kairos, es decir, del momento oportuno para llevarlos a cabo.

En efecto, durante la era clásica, este fue el eje central de la problematización moral, y es que la enorme satisfacción que la naturaleza imprimió sobre el acto sexual, acercaba a hombres y mujeres a un desorden emocional y físico que les hacía débiles, incapaces de cuidarse, de proteger las polis y esto hizo que la economía se gestara como una problematización sobre el placer (Foucault, Placeres 62).

De acuerdo con Mullina Cabrillana, algunos mitos de procedencia asiática, más precisamente de la Península del Penisute, la presentan enamorada del pastor Atis, quien iba a contraer matrimonio con otra mujer y Cibeles lo obliga a autoemascularse, acto que indicaría, además del debido control 
de las pasiones, el complejo de castración que surge luego de contraer matrimonio (277).

En el mito de Cibeles es interesante observar que la protección de la sociedad comenzaba desde el hogar, necesitaba del debido autocontrol y esto hizo de Cibeles un modelo de conducta para la enseñanza del sentido del kairos, no como regla de tiempo, sino como regla de prudencia, de que todo debe hacerse en el momento y lugar oportuno. Cibeles debió ser honrada desde el debido autocontrol de las pasiones y en la relación marital; también se le puede asociar con el primer discurso de la fidelidad recíproca.

\section{Conclusiones}

Los elementos encontrados, de acuerdo con la representación de los mitos asociados con la fertilidad y algunos de los dioses cercanos a la representación del oikos, si bien son propios de la era arcaica y comenzaron a transformarse a partir del origen de la filosofía, permiten rastrear algunas de las marcas fundamentales del discurso del oikonomikos de la era clásica.

Se pudo apreciar que durante la era arcaica se comenzaron a gestar algunos de los valores asociados al ideal de virtud del hombre económico y que en el carácter de su representación, aparecieron una serie de actividades que determinaron los ejercicios del núcleo familiar para la vida en el oikos.

En cuanto a la representación de Hestia, Hermes, Deméter y Cibeles, se puede encontrar como principal hallazgo que sus marcas se reflejan en el respectivo cuidado de todo aquello que fuese considerado propiedad, es decir, de todo aquello que perteneciera al campo doméstico, siendo así como aparece vinculado al contexto de la economía.

En primer lugar, se estudiaron algunos de los mitos asociados a Hestia desde la perspectiva de Jean Pierre Vernant y se encontró asociada a la 
calidez y al carácter pacífico necesario para la convivencia en el hogar, luego aparecen otros dioses como: Hermes, representando el papel del hombre que desde el exterior provee los elementos materiales y que además es pastor y guía.

Aparece también Deméter, asociada al cuidado y el amor incondicional hacia los hijos, aspecto que fue clave para la expansión de la cultura griega en diferentes polis. Finalmente Cibeles, tal vez una de las Diosas que representa mejor la significación de lo que posteriormente sería la economía en la era clásica, esta diosa de origen sentó las bases del discurso del autocontrol, del gobierno de sí en sentido kairológico, y por este medio de la protección de la ciudad de acuerdo con los debidos cuidados del hogar, de las cosechas, la propiedad y en general de todas las riquezas.

Todos estos elementos, permiten concluir que las características incluidas en la concepción de la economía de la era clásica encuentran su debido fundamento práctico en la imagen idílica de los dioses griegos. Las historias narradas antaño por estos poetas brindan suficientes argumentos para reconstruir la imagen del económico y la economía de dicho periodo histórico.

Adicionalmente, se encuentran algunos puntos que son pertinentes debatir y cuestionar con respecto a la significación actual, donde se evidencia que la economía es una ciencia ausente de su sentido vital; hoy son los modelos aquellos que pretenden dar la verdad sobre la práctica, cuando para los antiguos la práctica de la economía fundó las bases de un concepto relativo al debido control del cuerpo, de las pasiones, de la comida, la bebida y las práctica sexuales. 
Referencias de la investigación

Referencias principales

Finley, Moses I. The ancient economy. Los Angeles: University of Caifornia Press, 1974.

Foucault, Michel. "El Uso de los placeres". En: Historia de la sexualidad. Madrid: Siglo XXI Editores, 1986. . La Hermenéutica del sujeto. Madrid: Akal S.A., 2005. - "Las Tecnologías del yo". En: Obras Completas. Barcelona: Paidós, 1990. 45-94.

Gallego, Julián. "La Agricultura en la grecia antigüa. Los labradores y el despegue de la polis". Historia Agraria (2004): 15-35.

Hadot, Pierre. Ejercicios espirituales y filosofía antigua. Madrid: Ediciones Siruela S.A., 2006. - . No te olvides de vivir. Trad. Maria Cucurella Miquel. Madrid: Ediciones Siruela, 2010.

Heidegger, Martín. La Voluntad de poder como arte. Bogotá : Temis, 1977.

Howald, Ernst. “La Ética de los Griegos”. Ortega y Gasset, José. El espíritu de la letra. Madrid: Editorial Revista de Occidente, 1961. 31-46.

Mossé, Claude. "El Hombre y la economía". El hombre griego. Ed. Jean Pierre Vernant. Madrid: Alianza Editorial, 1995. 35-63.

Nietzsche, Friedrich. El origen de la tragedia. Trad. Eduardo Ovejero Mauri. Madrid: Editorial Espasa Calpe S.A., 2007.

Ortega y Gasset, José. Obras completas. Madrid: Revista de Occidente, 1969.

Soto, Gonzalo. "La Filosofía como forma de vida". Escritos (2009): 542576.

Vernant, Jean Pierre. El Hombre Griego. Trad. Pedro Badenas de la Peña. Madrid: Alianza Editorial, 1995.

. Entre Mito y Política. D.F.: Fondo de Cultura Económica, 2002. . Mito y pensamiento en la Grecia Antigua. Barcelona: Editorial Ariel, 1973.

. Mito y sociedad en la Grecia antigua. Madrid: Siglo XXI Editores, 2003. 
Referencias de la Antigüedad

Aristóteles. Ética nicomaquea. Madrid: Gredos S.A., 1985.

. La Política. Trad. Manuel Briceño Jáuregui. Primera edición.

Bogotá: Panamericana, 2000.

Metaphysica. Ed. W. Jaeger. Oxford, 1957.

Esquilo. Obras completas: Tragedias. Buenos Aires: Editorial Losada S.A., 1964

Hesíodo. Los Trabajos y los días. Madrid: Gredos S.A., 1978.

Homero. Himnos homéricos: La batracomiomaquía. Trad. J. Blanqué. Madrid: Ediciones Akal S.A., 1910.

Jenofonte. Recuerdos de Sócrates. Madrid: Gredos S.A., 1993. . Recuerdos de Sócrates. Madrid: Editorial Aguilar, 1967.

Ovidio. La Metamorfosis. Trad. Antonio Ruíz de Elvira. Barcelona: Bruguera S.A., 1983.

Platón. «El Primer Alcibiades.»Platón. Obras completas. Masachusets: Harvard University Press, 2005. 103a-151c.

. Fedón, Fedro. Trad. Luis Gil Fernández. Madrid: Alianza Editorial, 1998.

. «Timeo.» Ed. Bury, R. G. Obras Completas. Massachusetts: Harvard University Press, 2006. 3-15.

Sófocles. Trágedias. Trad. Assela Alamillo. Madrid: Biblioteca básica de Gredos, 2000. 69-127.

Referencias sobre conceptos griegos

Corominas, Joan. Diccionario etimológico. Madrid: Editorial Gredos, 1984.

Graves, Robert. Los mitos griegos I. Madrid: Alianza Editorial S.A., 1985.

Grimal, Pierre. Diccionario de mitología Griega y Romana. Madrid: Espasa, 2005.

Lleó Cañal, Vicente. "Atalanta e Hipómenes de Guido Reni”. Revista de Historia del Arte (2005): 141-146.

Martín, Rene. Diccionario crítico de mitología Griega. Madrid: Editorial Espasa Calpe S.A., 2005. 
Munilla Cabrillana, Glòria. "Una estatua representando a la diosa Cibeles hallada en la villa romana de 'Els Antigons', Reus”. Revista de Prehistòria i Antiguitat de la Mediterrània Occidental (1979): 277286.

Russo Delgado, José Antonio. Los Presocráticos: El logos (Heráclito). Lima: Fondo Editorial de la UNMSM, 2000.

\section{Referencias secundarias}

Bauman, Zygmunt. Trabajo, consumismo, y nuevos pobres. Barcelona: Gedisa, 2000.

Bentham, Jeremias. Deontología ó ciencia de la moral. Ed. M. J. Bowring. Trad. D.P.P. Vol. Tomo III. Paris: Librería de Gouas, 1839.

Bloch, Marc. La Sociedad feudal. Madrid: Ediciones AKAL, 2002.

Boutruche, Robert. "Los Campesinos y sus amos. Del gran dominio al señorío feudal”. Boutruche, Robert. Señorío y feudalismo. Los vínculos de dependencia. México: Siglo XXI Editores, 1995. 103-133.

Burke, Peter. El Renacimiento Europeo. Barcelona: Editorial Crítica S.I, 2000.

Caro Baroja, Julio. Las Brujas y su mundo. Madrid: Alianza Editorial, 2003.

Ceccarelli, Giovanni. "Economic thought in the middle ages". Ed. Lagerlund, Henrik. Encyclopedia of medieval philophy. Canadá: Springer, 2011. 283-290.

Chomsky, Noam. "Sobre la naturaleza humana, la economía y la democracia: del mercado y la libertad". El Viejo Topo 144 (2000): 21-28.

Descartes, René. Tratado de las pasiones del alma. Trad. Tomás Onaindia. Santiago: Editorial EDAF S.A., 2005.

Foucault, Michel. El Orden del discurso. Trad. Alberto González Troyano. Buenos Aires: Tusquest Editores SA, 2005. . La Arqueología del saber. Trad. Aurelio Garzón del Camino. Madrid: Siglo XXI Editores S.A., 1979. - Las Palabras y las cosas: una arqueología de las ciencias humanas. Buenos Aires: Siglo XXI Editores, 1968. 
Freud, Sigmund. El Malestar en la cultura y otros ensayos. Madrid: Alianza editorial, 1973.

Hadot, Pierre. No te olvides de vivir. Madrid: Siruela S.A., 2010.

Heidegger, Martín. ¿Qué es la metafísica? Buenos Aires: Siglo XXI Editores, 1987.

. Ser y Tiempo. Trad. Jorge Eduardo Riviera. Madrid: Trotta, 2009.

Hutcheson, Francis. "The principles of oekonomics and politiks". Hutcheson, Francis. A short introduction to moral philosophy. Glasgow, 1747. 255-346.

Kant, Immanuel. Crítica de la razón práctica. Trad. J. Rovira Armengol. Buenos Aires: La página SA, 2003.

Lipovetsky, Gilles. El imperio de lo efímero. Barcelona: Editorial Anagrama, 1996.

Marx, Karl. Trabajo asalariado y Capital. Barcelona: Paidós, 1848.

Nietzsche, Friedrich. Así habló Zaratustra. Madrid: Alianza Editorial, 1993. . El Anticristo. Madrid: Edimat Libros S.A., 2007.

Ortega y Gasset, José. Historia como sistema. Madrid: Editorial Sarpe, 1984.

Ricoeur, Paul. La Metáfora viva. Madrid: Ediciones Cristiandad, 2001. Rousseau, Jean Jacques. El Contrato social. Trad. Fernando de los Ríos. Madrid: Espasa Calpe S.A., 2007.

Sen, Amartya. Desarrollo y Libertad. Trad. Esther Rabasco y Luis Toharia. Barcelona: Ed Planeta, 2000. . Sobre ética y economía. Madrid: Alianza editorial, 2003.

Vallejo, Pablo. Antecedentes y Desarrollo del Modelo Neoliberal Globalista en las disciplinas de la Economía, Política y Relaciones Internacionales. 2008.

Weber, Max. Economía y Sociedad: Esbozo de sociología comprensiva. México: Ed. Fonde de Cultura Económica, 2008. 